OPEN ACCESS

Edited by: Bronwen Cowie, University of Waikato, New Zealand

Reviewed by: Eva M. Romera, University of Cordoba, Spain Nikol Rummel, Ruhr University Bochum, Germany

*Correspondence: Hanna Järvenoja hanna.jarvenoja@oulu.fi

Specialty section: This article was submitted to Educational Psychology, a section of the journal Frontiers in Education

Received: 26 June 2019 Accepted: 10 June 2020 Published: 28 July 2020

Citation:

Järvenoja H, Malmberg J, Törmänen T, Mänty K, Haataja $E$, Ahola S and Järvelä S (2020) A Collaborative Learning Design for Promoting and Analyzing Adaptive Motivation and Emotion Regulation in the Science Classroom. Front. Educ. 5:111 doi: 10.3389/feduc.2020.00111

\section{A Collaborative Learning Design for Promoting and Analyzing Adaptive Motivation and Emotion Regulation in the Science Classroom}

\author{
Hanna Järvenoja*, Jonna Malmberg, Tiina Törmänen, Kristiina Mänty, Eetu Haataja, \\ Sara Ahola and Sanna Järvelä
}

Learning and Educational Technology Research Unit, Faculty of Education, University of Oulu, Oulu, Finland

The aim of this paper is to introduce our current research design to study socially shared regulation processes in a science classroom where a collaborative learning design is implemented. The design is based on a self-regulated learning framework that provides opportunities and support for self-initiated regulation among individual learners and collaborative groups. It utilizes modern technology to structure and support regulated learning in the groups. The paper focuses on elaborating the research design, particularly from the perspective of motivation and emotion, by presenting the dual relationship between designing learning scenario that supports learners' motivation and emotion regulation with technology and researching the multifaceted role of motivation and emotion as they occur in collaborative learning. To do this, the paper first describes the entire collaborative learning design while paying attention to how technology can be utilized to support the awareness of motivation, emotion, and their regulation. Then, the focus shifts to considering the methodological principles and implementation of multimodal data gathered in relation to authentic collaborative learning tasks. A case example from a secondary school science classroom demonstrates possibilities for multimodal data use in analyzing motivation, emotion, and their regulation in collaborative learning. It also illustrates the dual role of the implemented technological $6 \mathrm{Q}$ support tool by showing how data collected from the students' use of the tool can be utilized in scientific analysis. The paper concludes by providing a short discussion about the current advancements of emerging technology in motivation and emotion research in the learning sciences highlighting the significance of sharing the theoretical premises of the research design as well as practical experiences from implementation of these designs for future research.

\footnotetext{
Keywords: collaborative learning, learning design, regulation support, emotion, motivation, SRL, socially shared regulation, multimodal methods
}

\section{INTRODUCTION}

Collaboration-based instructional approaches promote learning techniques for active and agentic learning (Hmelo-Silver, 2004). They support socially coordinated inquiry, knowledge creation, and stimulate higher levels of cognitive processing (Griffin et al., 2012; Sawyer, 2014), which are essential for twenty-first-century learning needs. Collaborative learning's benefits have been 
demonstrated by many researchers (Miyake, 1986; Roschelle and Teasley, 1995; Webb et al., 1995), and it is an increasingly valued teaching and learning practice in education. Ideally, during collaborative inquiry, learners monitor their understanding collaboratively to discover gaps in their knowledge base and actively implement appropriate study tactics and resources to overcome these gaps in coordination between the group members (Hmelo-Silver et al., 2013).

Increasingly, emerging technologies have been used to enable, stimulate, organize, support collaboration, and collaborative learning processes. In the computer-supported collaborative learning (CSCL) field, the focus has been on understanding how collaborative interactions emerge and are constituted (Wise and Schwarz, 2017). These processes have been supported through scripting and prompting, which are often used to facilitate productive interaction [e.g., Wang et al. (2017), Schnaubert and Bodemer (2019)]. However, prompts can also be used to explicitly raise learner's awareness of their collaborative learning processes at the individual and group level (Chanel et al., 2016). While there is a large body of empirical evidence indicating that learners benefit from scripts, prompts, and awareness tools in the context of CSCL (Schnaubert and Bodemer, 2019), it is unclear how the tools affect learning outcomes. These tools focus on supporting learners' cognitive and metacognitive processes, and the role of motivation and emotion have been largely ignored (Belland et al., 2013).

Regardless of the considerable progress made in the CSCL research field, groups still struggle to succeed in their collaborative efforts and in finding the strategies that would allow them to invest group members' learning potential in the shared learning processes (Järvelä et al., 2013). Although CSCL approaches have proven beneficial to learning, they are often motivationally and emotionally demanding as students are assumed to engage in higher-level thinking and interaction while taking greater responsibility for and control over their own and the group's shared learning processes (Mäkitalo-Siegl and Fischer, 2013). Hence, a substantial portion of the challenges learners face is related to cognitive hurdles that have socioemotional and motivational origins (Järvenoja et al., 2013). It has been argued that there is a need to emphasize supporting motivation and emotion in groups while groups share and build common ground on which to develop collaboration (Ludvigsen, 2016). This is particularly the case with adolescent students who experience novel and more demanding academic situations the same time they are going through developmental changes causing emotional hurdles (Gómez-Ortiz et al., 2016; Hollenstein and Lanteigne, 2018).

It is evident that the role of motivation and emotion in collaborative learning is more complex than just whether the individuals are motivated or simply dislike social interaction or dependence on others (Järvelä and Renniger, 2014). Emotional reactions to learning can change the way people approach collaboration, feel about the task, or interpret the social learning situation. Without actively and explicitly maintaining and enhancing motivation during learning, initial interest, or curiosity may not be enough to overcome challenges, especially when the premises and attitudes are unfavorable for collaboration. Theories of motivation and emotion in learning aim to explain this multifaceted functioning and the relationship between learners' beliefs and feelings in relation to learning (Pekrun, 2016). These theories have been utilized to explain why and how learners pay attention to, concentrate on, invest effort in, and persist in their academic learning (Volet and Järvelä, 2001; Schutz and Pekrun, 2007), as well as the precise challenges faced when collaborative groups do not reach their potential regarding cognitive processing (Hadwin et al., 2018).

Motivation and emotion regulation has been characterized as a fundamental part of effective collaborative interactions in the learning mechanisms of collaborative groups (Hadwin et al., 2017).

By engaging in emotion regulation as a part of regulated learning, learners address emotions, and their expression in the learning context and the way they experience them (Gross, 1998; Boekaerts, 2011; Goetz et al., 2015) and furthermore, they attempt to adjust the situation to better support their emotional well-being and learning. Emotion regulation is composed of active employment of strategies to reach the above-mentioned goal. Motivation regulation aims also to maintain learning and commitment to learning but focuses particularly on building up, maintaining, or restoring motivation in the learning situation (Wolters and Benzon, 2013). Research on the socially shared regulation of learning (SSRL) that extends the self-regulated learning (SRL) theory to include regulation processes taking place between collaborating group members has provided promising prospects to understand the function and role of motivation and emotion in collaborative interactions (Järvenoja et al., 2015; Hadwin et al., 2017). Via socially shared emotion regulation, group members can collectively ensure an emotionally solid (social) base on which academic tasks can be completed (Boekaerts and Pekrun, 2015; Pekrun, 2016). That is, when engaging in the socially shared regulation of emotion, several group members collectively engage in regulatory interaction that aims to release negative affect, dissolve emotional tension, unravel emotional experiences, or reduce negative emotional responses to socio-emotionally challenging situations that could hamper the group's learning and collaboration. The socially shared regulation of motivation, in turn, aims to purposefully maintain and restore a favorable motivational state during a learning process to achieve the learning goals (Boekaerts and Pekrun, 2015). Motivation regulation can be directed, for example, at initiating, restoring, strengthening, or redirecting interest, motivational goals, or self-efficacy beliefs (Wolters and Benzon, 2013). What makes both motivation and emotion regulation socially shared is the group members' coordinated and complementary efforts, which contribute to regulating the groups' motivational and emotional state (Järvelä et al., 2017).

Awareness of emotional reactions, challenging situations, and motivational conditions is a premise for groups to activate regulation on a social plane (Diamond and Aspinwall, 2003; Op't Eynde and Turner, 2006; Järvenoja et al., 2015). However, research on SSRL focusing on emotions and motivation indicate that group members do not always recognize the need for regulation or display the need for it explicitly on a social plane, resulting in challenges for SSRL to emerge (Koivuniemi et al., 
2017; Hadwin et al., 2018) Based on previous research, we claim that providing support for increasing awareness can foster the group members to jointly activate these processes (Bakhtiar et al., 2018; Järvenoja et al., 2018a).

While acknowledging the critical role of emotion and motivation in contemporary learning, the aim of this paper is to introduce our current research design which relies on our former process-oriented approach and aims at implementing empirical studies on socially shared regulation processes in a science classroom. The research design is implemented in relation to a collaborative learning design, which is also introduced in the paper. The collaborative learning scenario is designed to promote and support socially shared regulation processes in authentic collaborative learning settings. In this paper, we focus on students' motivation and emotion regulation, describe the dual relationship between supporting motivation and emotion regulation, and analyze the multifaceted role of motivation and emotion as they occur in collaborative learning. In the collaborative learning design, we implement the SRL framework (Zimmerman, 2000; Hadwin et al., 2017), which affords learners opportunities to take responsibility for their own learning and offers possibilities to support learners' emotion and motivation regulation with technology. We will first discuss the entire collaborative learning design while paying attention to pedagogical structures and how technology can be utilized to support the awareness of motivation, emotion, and their regulation. Then, we shift to considering the methodological principles that support the aim of studying regulated learning from multimodal data collected from authentic collaborative learning settings. To concretize these methodological principles, we conclude with a case illustration demonstrating the possible implementation of multimodal data in analyzing motivation, emotion, and their regulation in collaborative learning. The data used for the example were obtained from a secondary school science classroom where the collaborative learning design was implemented.

\section{A COLLABORATIVE LEARNING DESIGN FOR PROMOTING MOTIVATION AND EMOTION REGULATION AS A PART OF COLLABORATIVE SCIENCE LEARNING}

Motivation and emotion regulation do not emerge in isolation but are related to the individual group members' wider motivational structures, as well as context, situation, and cognitive processes (Weiner, 1985). Although the multifaceted function and role of motivation and emotion in collaborative learning are increasingly acknowledged (Lajoie et al., 2015; Hadwin et al., 2017; Järvenoja et al., 2018a; Winne, 2018), supporting motivation and emotion has not been emphasized when designing learning environments (Belland et al., 2013). However, some researchers [e.g., Janssen and Bodemer (2013)] have considered motivation and emotion as a part of the CSCL framework, focusing on increasing group members' awareness of cognitive and social processes. Other researchers, such as Bakhtiar et al. (2018), have been developing scripts that not only enhance group members' awareness of possible socio-emotional challenges but also prompt their awareness of possible strategies that could be used to overcome such challenges.

Järvelä and Renniger (2014) have stated that it is not enough to consider how to support motivation and emotional engagement of learners who have negative emotions and low motivation. They have argued that when designing collaborative learning tasks, deliberate attention should also be paid to on-going process and how those who are initially engaged or gradually building a situational interest can be encouraged to maintain their motivation and deepen their interest during the learning process. Continuous commitment to learning goes beyond the initial motivation to volitional attempts to maintain, strengthen, and direct motivation to circumstances where motivational and emotional commitment is confronted by situational circumstances (Corno and Kanfer, 1993). When designing formal learning settings, guiding principles should also consider how spaces to practice motivation and emotion regulation in action can be created (Järvelä et al., 2020). Proper and timely support for motivation and emotion regulation initiates opportunities for this. It also provides learners possibilities to internalize concrete techniques to implement during future learning when motivational and emotional commitment is jeopardized, but external support is not available (Fischer et al., 2013).

To follow this line of argument, we have created a collaborative learning design focusing on promoting and studying motivation and emotion regulation, along with a wider focus on the regulation of collaborative learning. To capture the dynamics of students' individual motivational and emotional factors during the learning process, we utilize an ecologically valid learning context and research design that enables us to assess authentic learning challenges and embedded processes of motivation, emotion, and their regulation. We implemented the design in a study of secondary school students $(\sim 13$ years of age, $N=94,36$ male, 58 female $)$ and their science teachers. All the participants were from a same comprehensive school located to an urban area in the Northern Finland and had an equal socio-economic background. The students' were participating in the study while they engaged in collaboratively studying wave motion and its various physical manifestations for a 7 -weeks study period. The science topic was derived from the national physics curriculum and focused specifically on light and sound as elements of wave motion. Ninety-four students from five seventh-grade classes and four teachers volunteered to participate. The participating students were divided into 30 heterogeneous groups based on their previous science grade. Students who did not agree to participate in the research studied the topic following the same pedagogical structure but collaborated in separate groups and in a different classroom. During the data collection period, students participated in four collaborative learning sessions and completed one individual exam and one collaborative exam.

The collaborative learning design is built on the idea of a "flipped classroom." Recently, the flipped classroom concept has been gaining considerable attention due to its potential to facilitate the regulation of learning (Jovanovic et al., 2019). The use of a flipped classroom in collaborative learning creates a learning setting in which students are provided 
opportunities to take responsibility for their own learning by familiarizing themselves with the content knowledge beforehand to prepare for collaborative learning. Collaboration during school lessons, in turn, promotes interaction between students via sharing information, searching for meanings and solutions, and maintaining a shared understanding of the problem (Iiskala et al., 2011). Accordingly, a flipped classroom combines conventional face-to-face classroom learning with preparatory activities to optimize collaborative learning and knowledge construction. The role of the teacher is to design opportunities for independent learning and act as a facilitator supporting collaborative learning activities in face-to-face settings that are also supported with technology. However, how this type of learning setting challenges and promotes motivation, emotion, and their regulation is yet to be well-understood.

In our collaborative learning design, the flipped classroom structure and the collaborative work were coordinated by using a technology-based environment called Qridi ${ }^{\circledR}$, which provided the main structure for the entire 7-weeks learning period, as well as for each lesson. Students used the Qridi ${ }^{R}$ platform (https://kokoa.io/products/qridi) with tablets to structure their collaboration and increase awareness of the regulation of learning in each lesson. In the $\operatorname{Qridi}^{\circledR}$ environment, they were able to check, for example, the phase of the lesson. Qridi ${ }^{\circledR}$ offers tools for formative evaluation, an environment in which learners can perform self, peer, and group evaluations and where teachers can also evaluate students' learning. In our learning design, Qridi ${ }^{\circledR}$ was tailored to switch the focus from the evaluation of learning to structure and increase students' awareness of the collaborative learning task phases in general and, specifically, supporting their awareness of the regulation of learning.

The structure of each lesson was purposefully designed to follow the same structure (Figure 1), although the focus and nature of the exercises varied as the students' understanding of the subject deepened. With the help of the Qridi ${ }^{\circledR}$, the structure was visible for the students from the very beginning, which provided them possibilities to prepare, control, and coordinate their collaboration not only within but also across the lessons. The first basic principle was that based on flipped classroom principles, the students independently studied the upcoming topic in their science textbook prior to each lesson. When students entered the classroom, the teacher first introduced the new topic to the students and ensured that each student had enough knowledge about the topic to engage in collaborative learning. Second, the students were prompted to prepare for the collaborative work by responding to a situated $6 \mathrm{Q}$ tool in the Qridi ${ }^{\circledR}$ environment (see chapter 3.1. for more detailed description of the $6 \mathrm{Q}$ tool). As regulation of learning requires meta-level consciousness of the current situation and the need for regulation (Hadwin et al., 2017), the 6Q tool targets to increase the students' awareness of their current motivational and emotional state. This can help students to create meta-level consciousness of the motivational and emotional aspects calling for regulation in that particular lesson. For example, identifying a negative emotional state can make the student realize that "something is wrong" and needs regulating. Third, to emphasize and make explicit the planning and goal setting phase of regulated learning, the students were prompted to discuss and commit to shared goals and plans for their collaborative learning for that lesson (What is the goal for your collaboration? What will you do to achieve your goals?). Shared plans and goals were written down in Qridi ${ }^{\circledR}$. Altogether, these three activities formed an initiation phase for each lesson and prepared the students for the collaborative work.

After the initiation phase, most of the lesson time was devoted to collaborative work. When designing learning contexts that promote regulation and, in particular, motivation and emotion regulation, it is crucial that both the structure and the content of the planned tasks optimally challenge the students (Perry, 1998). From the collaborative learning perspective, tasks that call for multiple perspectives and where the meaning needs to be negotiated through interactions with others have been developed for decades (Von Glasersfeld, 1998). In the current collaborative learning design, the implementation of the flipped classroom structure aimed to provide independence and room for collaborative groups to plan and coordinate their joint working whilst still ensuring individual learning. Each collaborative learning task consisted of mathematical calculations and hands-on scientific experiments. The content and exercises of the tasks were designed with assistance from science teachers to ensure they covered the required subjects and content, and the researchers ensured that the tasks provided possibilities for the regulation of learning. In one learning task, for example, the task was to do experiments on the light and sight. The groups were provided with four different main themes for investigation (1. Investigate illumination by changing the distance of the light, 2 . Investigate intensity of light, 3 . Investigate propagation of light, and 4. Investigate how reflection is related to sight). A flashlight, a set of experiments and related materials as well as guiding questions and instructions were provided to the groups. The groups planned and executed the experiments related to overall task by implementing each group member's prior knowledge. This knowledge was gained in the preparatory homework activity in which the group members independently studied the factual knowledge on light and sight. During the collaborative working individual understanding was shared to co-construct more profound and shared understanding of the topic.

When the collaborative working time was over, the students returned to the $\operatorname{Qridi}^{\circledR}$ to test their individual knowledge by completing a multiple-choice questionnaire about the key concepts of the day's topic and repeated the $6 \mathrm{Q}$ tool reflection structure in the reverse order. First, the students together discussed the group's goal achievement (How did you achieve your goals for collaboration? Why?) and second, filled in their individual reflections on their motivational and emotional state. Each lesson ended with teacher-led discussions and conclusions and the provision of homework, which, according to flipped classroom principles, was always the new topic for the next lesson. Finally, from the regulated learning perspective, we have argued that the learning tasks and projects should be long enough to provide a genuine need for taking control over their own learning processes. Hence, in our collaborative learning design, the students were engaged in a several-week learning period, and each collaborative learning session lasted for $90 \mathrm{~min}$ to 


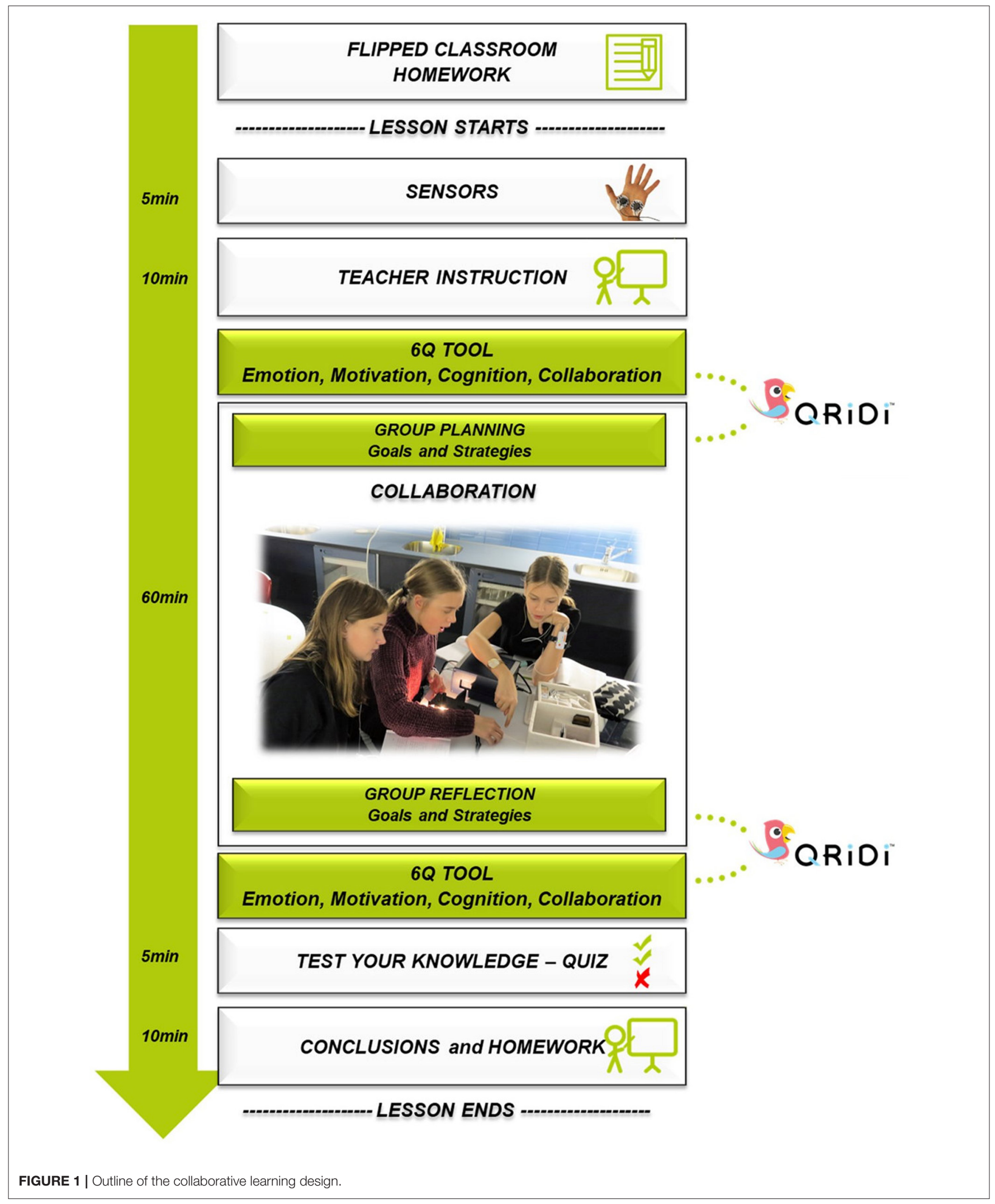


provide enough possibilities for regulation within and across the lessons.

The collaborative learning design aligns closely with the principles of SRL theory regarding the independence of the learner and the length and nature of the learning tasks. In practice, the alignment of the learning design and SRL theory is realized, for example, in how the responsibility of the learning is switch to the learner by assuming that they study the content knowledge prior to the collaborative learning sessions. Each session is structured according to the regulated learning cycle (planning, monitoring, evaluating) (Hadwin et al., 2017), and this cycle was also explained to the students in the beginning of the 7-weeks study period. The students were also familiarized with the idea of "taking charge of own learning" and explained how regulation of learning encompasses motivation and emotion regulation in addition to the regulation of cognition (Järvelä et al., 2016). The regulated learning cycle is related to the complete study period but was visible also in the sub-structures of the design. This is, the regulated learning cycle was present in the structure of each collaborative learning session, in individual working and in the use of $6 \mathrm{Q}$ tool. The students were explained that emotions and motivation can be regulated in any phase of the regulated learning cycle. To ensure the accurate comprehension of the $6 \mathrm{Q}$ tool items, each single item used was explained to the students and the meanings of the items were elaborated carefully. Also, it was emphasized that there are no right or wrong answers and the students' responses for the $6 \mathrm{Q}$ tool are not going to influence their physics grades.

To summarize, the design provides a framework for teachers and researchers to structure collaborative learning in a meaningful way that also considers the role of motivation and emotion in the learning process. The long-term design and unvarying overall structure, with varying but related content and exercises, allows the study of fluctuating emotional processes and the role of motivation integrally with the context and the learning process. Real-life learning situations enable grasping the multiple layers of motivation and emotion that are realized in the regulatory actions in situ (Volet et al., 2009; Järvenoja et al., 2015). However, we were also interested in reaching the students' own situation-specific appraisals and interpretations as they are essential to understanding the reasons for certain observable activities. The presented learning design provides a relevant opportunity for this as the students repeatedly evaluated their situational motivation and emotion in relation to learning and collaboration. In the next chapter, we elaborate on the role of awareness in collaborative groups' motivation and emotion regulation and pinpoint how the students' evaluations of their motivational and emotional state, as well as their cognitive abilities and collaboration, gathered with the 6Q tool, served as a support tool for regulation.

\section{SUPPORTING COLLABORATIVE GROUPS' REGULATED LEARNING WITH TECHNOLOGICAL TOOLS}

Collaboration skills are important to achieving successful learning, but they tend to be neglected and undermined when collaborative learning is implemented (Mullins et al., 2011; Baker, 2015; Kuhn, 2015; Kirschner et al., 2018). Neglecting these skills has contributed to computer-based learning environments and technological learning tools not reaching their full educational potential. Prior research clearly indicates that many students are unable or unwilling to regulate their learning (Shapiro and Niederhauser, 2004; Azevedo, 2005). Although different types of tools and technologies are widely used in the field of CSCL, students and teachers do not always recognize the opportunities they provide for (practicing) the regulation of collaborative learning processes (DiDonato, 2013; Järvelä et al., 2013). This has led SRL researchers to emphasize that supporting regulation is fundamental to effective individual learning (Cohen, 1994; Azevedo, 2015), as well as collaborative groups (Järvelä et al., 2016). For example, Wang et al. (2017) showed how adaptable collaboration scripts can be effective for regulation activities. They found that an adaptable script increased the students' use of monitoring and reflection activities, but it did not have an effect on planning. They concluded that adaptable collaboration scripts decrease the need for planning but provide more opportunities for monitoring task progress. Their results show that an adaptable script facilitates learners' use of self-regulation through the promotion of co-regulation processes. Similarly, Schnaubert and Bodemer (2019) incorporated metacognitive group awareness information into CSCL to help build students' confidence in their ability to regulate the collaborative process. They found that support provided in the form of visualizations has positive effects on joint regulation but not on the learning outcomes.

Following research-based evidence, researchers have developed technological tools from different premises to prompt and support regulation explicitly (Azevedo and Witherspoon, 2009; Miller and Hadwin, 2015). For example, some of the technological platforms are designed based on the principles of a certain pedagogical structure, such as inquiry learning, but include elements that support regulation, such as WeSpot (Mikroyannidis et al., 2013), which can be tailored to support the regulation of learning. Some other learning platforms are more general in their basic principles but allow researchers or course instructors to use and modify the tools available to create regulation support according to the specific purpose and context. For example, in their study of higher education students' regulation during a semester-long undergraduate course, Bakhtiar et al. (2018) modified the Moodle environment, which was used as an online environment for the coursework, to script motivation and emotion regulation. Their version of the Moodle included forms for students to plan collaboration activities, as well as consciously consider what type of emotional challenges they anticipated in relation to their collaboration. Some technologies, such as nStudy (Winne and Hadwin, 2013), integrate SRL theory principles, and hence, regulation support is embedded in their structures. Finally, the technological tool can be designed to support regulation, for example, the S-REG tool, which provides targeted support for groups' SSRL based on the motivational, emotional, and cognitive challenges the individual group members become aware of with the help of the tool (Järvelä et al., 2016). 
In complex learning settings that emphasize students' individual responsibility and the regulation of learning, students could benefit from the explicit support of motivation and emotion that exceeds the overall regulated learning support. The hallmark for the successful regulation of learning is that the learner becomes aware of the need for regulation. This awareness is followed by an accurate recognition of the target of regulation, whether it is related to cognitive aspects or originates from emotional challenges, motivational issues, or both (Malmberg et al., 2015). Only then can the learner reliably choose and apply proper regulation strategies and eventually adapt the SRL process and take charge of the learning process. Regardless of the form of technology or tool aiming to support motivation and emotion, the main principle of this support can, hence, be simplified into two main principles: increasing learners' awareness of the need for motivation and emotion regulation and accurately recognizing how they can regulate the situation (Järvenoja et al., 2018b; Järvelä et al., 2020).

\section{Q Tool for Motivation and Emotion Regulation Support}

Motivation and emotion do not function in isolation in collaborative learning. Rather, cognitive, social, emotional, motivational, and contextual variables interact with each other in a multifaceted, dynamic manner (Thompson and Fine, 1999). Targeted support for motivation and emotion regulation provides situated support for motivation and emotion during collaborative inquiries but in relation to cognitive processes (Järvenoja et al., 2017). Hence, in the current collaborative learning design, we targeted explicitly prompting students' awareness of their situational motivation and emotion simultaneously with the awareness of cognitive interpretations with the $6 \mathrm{Q}$ tool. The development of the $6 \mathrm{Q}$ tool was based on prior research on supporting awareness of different regulation targets (see Järvelä et al., 2016).

The guiding idea of the $6 \mathrm{Q}$ tool was to promote students' awareness of targets that potentially could call for active regulation. This was done with repeated evaluations of their emotional state and level of motivation simultaneously with cognitive ability evaluations and an appraisal of the current collaboration. Hence, $6 \mathrm{Q}$ prompts students' awareness of all the possible targets for regulation in parallel but explicitly recognizes each target to avoid the possibility of one undermining the others. In practice, the 6Q tool consists of six 0-100 sliderscale questions where students estimate their task understanding (Schraw and Dennison, 1994), perceived task difficulty (Efklides et al., 1998), emotional activation and valence (Pekrun et al., 2007), situational interest (Tapola et al., 2013), and perceptions of group work (Volet, 2001). In terms of motivation and emotion, Figure 2 shows how, at the beginning and the end of the group work, the students are instructed to individually evaluate their emotional state and level of motivation: how they are currently feeling (positive-neutral-negative and deactivatedneutral-activated) and how the task seems to them (boringneutral-interesting and difficult-neutral-easy).

Technological support tools often require becoming familiar with the tool and learning how to use it to achieve the intended supportive effect it can provide (Mayer and Moreno, 1998). Also, there is a risk of the tool being so "heavy" that it can even move the target away from the actual learning situation it is aiming to support. The 6Q tool implements a single-item approach for each variable to prevent the tool from being unnecessarily intrusive. By selecting a single-item measure approach, we balance between the dual purposes of the tool use; the 6Q tool supports self-awareness but avoids unnecessary intrusiveness by keeping the focus on the collaborative learning task. As for data validity, Goetz et al. (2016) argue for single item measures, particularly when measuring state-like situation-specific and varying motivational experiences. Single-item measures have been found to be reliable and useful in several SRL studies conducted during learning [e.g., Ainley et al. (2002), Ainley and Patrick (2006)] even if psychometric attributes are weaker compared to traditional multi-item questionnaires where the reliability and validity test between the items within a scale can be computed with common statistical analyses. When the measures are related to a specific situation or task, and the measure is used by a participant more than once, a questionnaire needs to be simple enough to diminish the effects of the questionnaire itself, so it more reliably measures the actual attitudes of the participants. In addition, as the Qridi ${ }^{\circledR}$ environment was already familiar to the students, the $6 \mathrm{Q}$ tool did not require too much effort from the students to use it. Accordingly, a slider scale and a single-item solution appeared to be the most functional and valid solution as it worked well with the Qridi ${ }^{\circledR}$ design and were easy and fast to use. This solution enabled a repeated use of the $6 \mathrm{Q}$ during the classroom lessons without intrusiveness and decrease in reliable responding. Finally, the single-item solution allowed to capture the situational variation in motivational and emotional states within a person.

\section{COLLECTING AND ANALYZING MULTICHANNEL DATA WHEN UTILIZING THE COLLABORATIVE LEARNING DESIGN-ZOOMING ON MOTIVATION AND EMOTION}

In this chapter, we move from the learners' perspective to a research perspective to illustrate what types of data related to motivation and emotion we gain by implementing the collaborative learning design. In the following, we focus on presenting examples of the possible use of different data sources instead of reporting detailed results. In the examples, we consider the multi-componential and multifaceted nature of motivation and emotion, such as the variation and fluctuation in emotional states within and across individuals, and the relationship between affective experiences and motivational or cognitive aspects and provide analytical ideas for further research [e.g., Bakhtiar et al. (2018), Goetz et al. (2016), Ketonen et al. (2018), Moeller et al. (2018)]. Instead of focusing solely on individuals, we are particularly interested in group-level processes; depicting how socially shared motivation and emotion regulation function and fluctuate during collaborative learning situations. Considering how motivation, emotion, and their regulation are situated and embedded in subjective appraisals, contexts, and cognitive processing, 


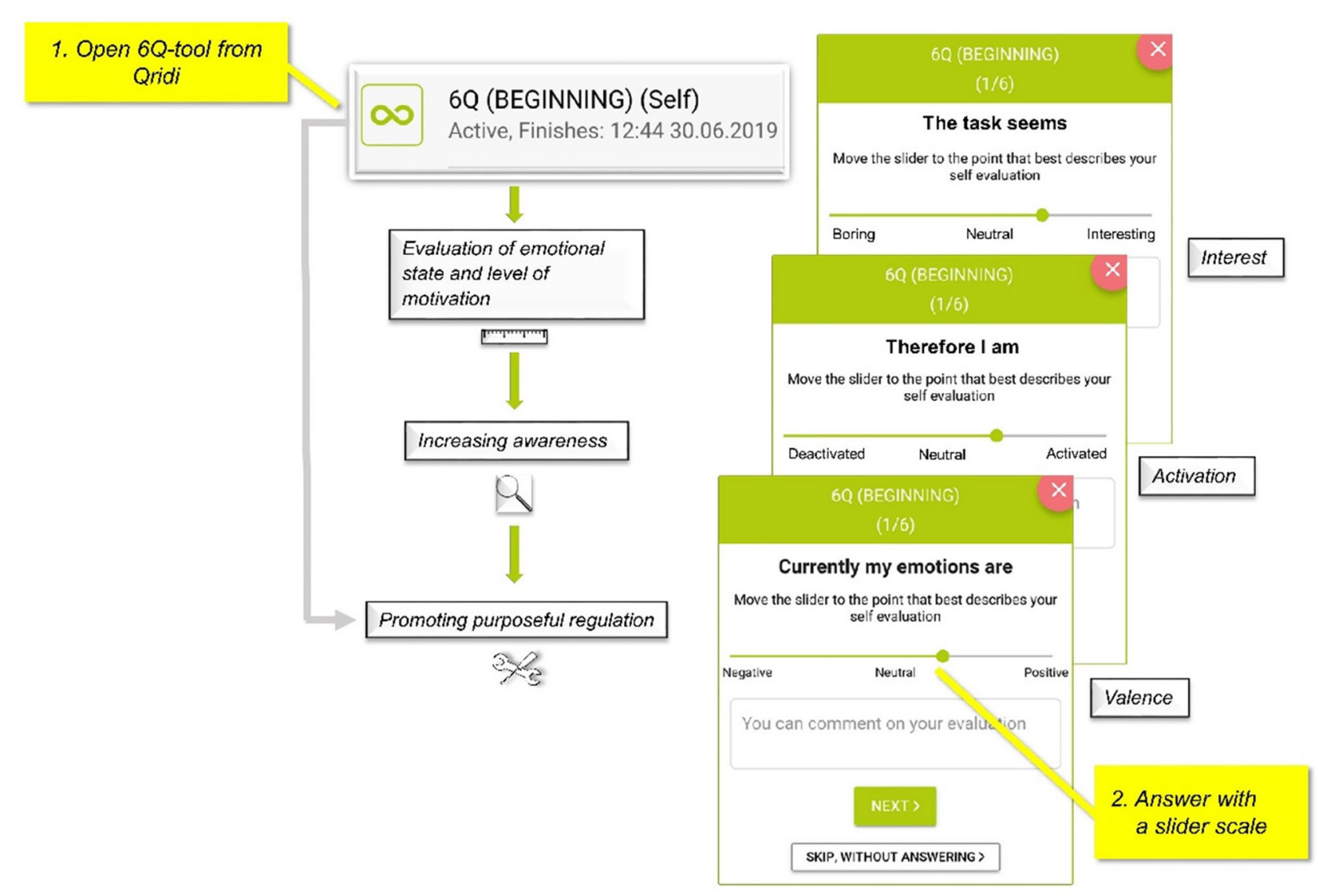

FIGURE 2 | An example of the 6Q tool's structure in terms of its motivational and emotional aspects. By increasing students' awareness of their situational emotional and motivational state, the $6 \mathrm{Q}$ tool prompts students' to actualize motivation, and emotion regulation when needed.

research designs that capture the variety of meaningful indicators are needed.

As the students study according to our collaborative learning design, multiple data sources produce a multimodal data corpus that encompasses data on motivational, emotional, and cognitive aspects on the individual and group level. Prior to beginning the study, the participating students responded to trait-type selfreports about their SRL strategies and task interest (Cleary, 2006), metacognitive awareness (Schraw and Dennison, 1994), self-efficacy (Usher and Pajares, 2008), and group assignment appraisals (Volet, 2001), each validated and used extensively in earlier research (see Table 1 for the different measures utilized and their features). The purpose of these measures was to gain an overall understanding of the students' motivational traits and emotional and regulatory underpinnings. The motivational and emotional appraisals, expectancies, values, beliefs, and goals collectively form the (pre)conditions for motivation and emotion regulation and regulated learning (Pekrun, 2016; Winne, 2019). The learning situations were constituted based on these conditions, indicating that the learner's approaches and decision-making processes were personalized by prior experiences and events over time, but they were also shaped in the course of action, making them sensible for the situation (Hadwin et al., 2017).

During the 7-weeks multichannel data collection process, students' collaborative work was followed by video recordings and individual-level physiological measures. To capture the learning activity in its natural setting and obtain multimodal process data related to the different cognitive, emotional, and motivational components, the learning session was recorded using four Insta360 Pro video cameras placed in the classroom and separate microphones placed in front of each group. Video data provides contextualized data through different channels (i.e., voice, facial expressions, and interactions) from the different operations shaping the groups' shared and individual motivational and emotional states. Operations that can be tracked from video data cover verbal and nonverbal emotional expressions, socioemotional interactions, actualized motivation, and emotion regulation. To capture students' covert physiological reactions during the learning situation, such as students' physiological reactions related to emotional activation, their electrodermal activity (EDA) and heart rate (HR) were recorded via Shimmer3 GSR + devices (Figure 3). The GSR+ electrodes were attached on the palm of the non-dominant 
TABLE 1 | Self-report data collected prior to the 7-weeks science learning period.

\begin{tabular}{|c|c|c|c|}
\hline Theoretical focus & Specific construct & Data source & Sample $N$ \\
\hline Self-regulation & SRL strategies & Questionnaire Cleary, 2006 & 94 \\
\hline Metacognition & Awareness & Questionnaire Schraw and Dennison, 1994 & 94 \\
\hline Motivation & Task interest & Questionnaire Cleary, 2006 & 93 \\
\hline Motivation & Self-efficacy & Questionnaire Usher and Pajares, 2008 & 93 \\
\hline Collaboration & Appraisals of collaborative working & Questionnaire Volet, 2001 & 93 \\
\hline Outcome & Individual performance & Physics exam designed by teachers & 94 \\
\hline Outcome & Group performance & $\begin{array}{l}\text { Collaborative exam task designed with } \\
\text { teachers }\end{array}$ & $30^{\star}$ (groups) \\
\hline
\end{tabular}

${ }^{\star}$ Due to absences of students from the group exam, some group compositions were adapted from the original.

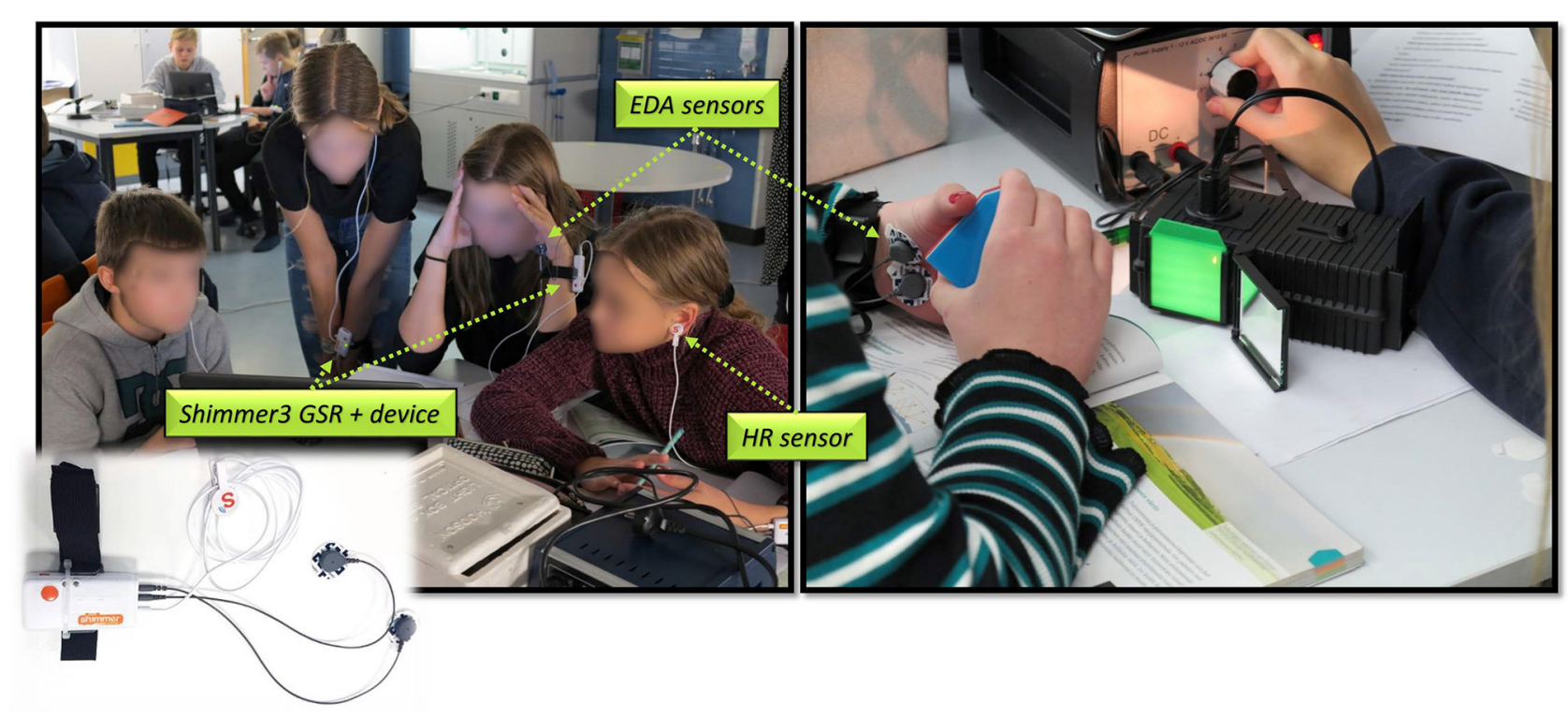

FIGURE 3 | An illustration how the students wore the Shimmer3 GSR+ devices in the classroom during collaborative learning.

hand and measured the students' EDA. HR was measured with an optical pulse sensor placed on the ear lobe. According to the students' experiences and field observations, the sensors did not restrict students' required motoric actions during the lessons. Hence, in our experience, the Shimmer3 is a functional and relatively unobtrusive device to collect continuous, high granularity process data on physiological activity in classroom contexts. The EDA measures, for example, have already been used to track students' general physiological activation level during learning sessions (Pijeira-Díaz et al., 2018). It has been implemented also in studies on learners' short-term emotional responses (Dawson et al., 2007). Combined with video data, EDA data enables to track physiological emotional reactions in relation to the regulatory interactions. Though certain challenges remain, EDA and HR provide intensive temporal data about physiological activity that can be related to data on motivational, emotional, and cognitive processes during task execution (Pecchinenda and Smith, 1996; Kreibig and Gendolla, 2014; Efklides et al., 2018), and have potential as a new data channel when learning processes are studies in authentic contexts. Altogether, the collaborative learning design produced a versatile data corpus, which is presented in Table 2. All the required equipment was brought to the school and installed in the science classrooms to capture the learning activity in its natural setting (Table 2). In addition, after the learning period, we measured the students' learning outcomes at both the group and the individual level.

As one of the multiple data sources, we used the 6Q tool to collect students' situation-specific motivational, emotional, and cognitive experiences related to each collaborative session before and after the collaborative work (Table 3). With 6Q tool data, we can capture group members' varying subjective motivational and emotional experiences that are impossible to capture with other process data modalities. Particularly, 6Q tool data provide a possibility to explore situational variations in individuals' motivational state and the valence-activation space (Pekrun, 2016; Törmänen et al., 2020). From the motivational perspective, the $6 \mathrm{Q}$ tool taps situational variation in self-efficacy beliefs and interest. Of particular interest, however, are measures 
TABLE 2 | Process data collected during the science learning period.

\begin{tabular}{|c|c|c|c|}
\hline Theoretical focus & Specific construct & Data source & Sample $N$ \\
\hline $\begin{array}{l}\text { Emotions } \\
\text { Motivation } \\
\text { Cognition } \\
\text { Collaboration }\end{array}$ & $\begin{array}{l}\text { For example: socio-emotional } \\
\text { interaction, socially shared motivation, } \\
\text { and emotion regulation }\end{array}$ & $\begin{array}{l}\text { Video } \\
\text { (Insta360 Pro camera, separate } \\
\text { microphones) }\end{array}$ & $\begin{array}{l}7 \text { sessions } \times 90 \mathrm{~min} \times 30 \text { groups } \\
=212 \mathrm{~h}\end{array}$ \\
\hline Emotions & Physiological arousal and activation & $\begin{array}{l}\text { Electrodermal activity } \\
\text { (Shimmer3 GSR+) }\end{array}$ & $\begin{array}{l}7 \text { sessions } \times 90 \mathrm{~min} \times 84 \text { students } \\
=582 \mathrm{~h}\end{array}$ \\
\hline Outcome & Content knowledge & $\begin{array}{l}\text { Fact test } \\
\text { (Qridi) }\end{array}$ & $7 \times 94=289 / 376$ responses $^{*}$ \\
\hline
\end{tabular}

*Due to individual students' occasional absences from the lessons, the sum of the responses is lower than expected.

tapping emotional dimensions, as the 6Q tool guides the students to evaluate, in addition to the current emotional valence, how deactivating vs. activating they interpret the current emotional state. By providing data from two modalities of the emotional experience, the valence that separates positive emotions from negative ones, and the activation that relates emotions to physiological arousal and learning activity (Ben-Eliyahu and Linnenbrink-Garcia, 2013; Boekaerts and Pekrun, 2015), the 6Q tool establishes a mediating data source that connects and combines the other data sources to study the relationships between motivation, emotional states, and actualized motivation and emotion regulation in collaborative learning (LinnenbrinkGarcia et al., 2016).

To summarize, all the data modalities presented in Tables 1-3 provide data that can be considered to contribute to motivation and emotion regulation in the context of collaborative learning, but they follow different theoretical, conceptual, and methodological assumptions, as well as differences in the granularity of the analysis unit or differences in temporal nature. While we have argued that multimodal data collected in an authentic context are needed to capture motivation, emotion, and their regulation in their natural environment, another question that arises is how can we proceed with the varying data modalities. The following case example demonstrates how we have begun to combine different data modalities with $6 \mathrm{Q}$ tool data and how they can be triangulated to obtain profound information related to the students' motivational and emotional conditions and variations throughout the learning session.

Figure 4 illustrates, with one learning session of a case group consisting of three students (one male, two female), how the general self-report data provide a means to understand students' trait-like motivational conditions (i.e., science interest and selfefficacy) that are present when they enter the collaborative learning situation, while the $6 \mathrm{Q}$ tool produces cumulative data on students' situation-specific experiences. In the case example, the group members' motivational conditions are heterogeneous; Student 1 self-reports her interest and self-efficacy regarding science to be high with means of 4.0 and 4.1 , respectively, on a Likert scale from one to five, while Student 2 indicates they are low $(M=1.8$ and 2.4 , respectively), and Student 3 places himself on medium level ( $M=3.2$ and 3.3 , respectively). Hence, motivational conditions for the case group's collaborative learning and socially shared regulation of motivation and
TABLE 3 | $6 \mathrm{Q}$ tool data components.

\begin{tabular}{llll}
\hline $\begin{array}{l}\text { Theoretical } \\
\text { focus }\end{array}$ & Specific construct & Data source & Sample $\boldsymbol{N}$ \\
\hline Cognition & $\begin{array}{l}\text { Task understanding and } \\
\text { perceived task difficulty }\end{array}$ & $\begin{array}{l}7 \text { sessions } \times 2 \\
\text { times } / \text { session } \times 94 \\
\text { students }=801 / 940 \\
\text { responses }\end{array}$ \\
Emotion & $\begin{array}{l}\text { Valence and activation } \\
\text { Motivation }\end{array}$ & $\begin{array}{l}\text { Situational interest } \\
\text { Collaboration }\end{array}$ & $6 \mathrm{Q}$ tool \\
& $\begin{array}{l}\text { perceptions of group } \\
\text { work }\end{array}$ & $6 \mathrm{Q}$ tool & \\
& & & \\
\hline
\end{tabular}

"Due to individual students' occasional absences from the lessons, the sum of the responses is lower than expected.

emotion are different than if all the group members, for example, shared the same interest and efficacy level.

Situated 6Q tool data capture students' situational emotional experiences (valence and activation) and task interest with a slider scale from 0-100. Thus, it not only sheds light on the situational motivational and emotional preconditions prior to each collaborative learning session but also reveals how these modalities change in the course of collaboration. In the case example, the students' situational emotional experiences and interest seem to correspond to their general motivational conditions regarding science learning at the beginning of the collaborative work. This is shown in their evaluations of emotional valence and activation, as well as interest, which are illustrated in Figure 4. Student 1, for example, seems to maintain the same positive evaluation in the situational level as she initially indicated in self-reports; her emotional state is fairly positive (64) and she is also fairly interested and activated (64 and 62, respectively). In turn, Students 2 and 3 are indicating negative valence ( 8 and 35 , respectively) with medium level of activation (46 and 48, respectively) and interest (51 and 50, respectively). However, towards the end of the learning session, group members begin to evidence more variation, indicating that the collaborative work and interaction start to gradually influence their situational motivational and emotional interpretations (Figure 4). At the end of the collaboration, Student 1 indicates even more positive valence (87) with fairly high levels of activation (73) and interest (80). Student 2 shows a slight increase 


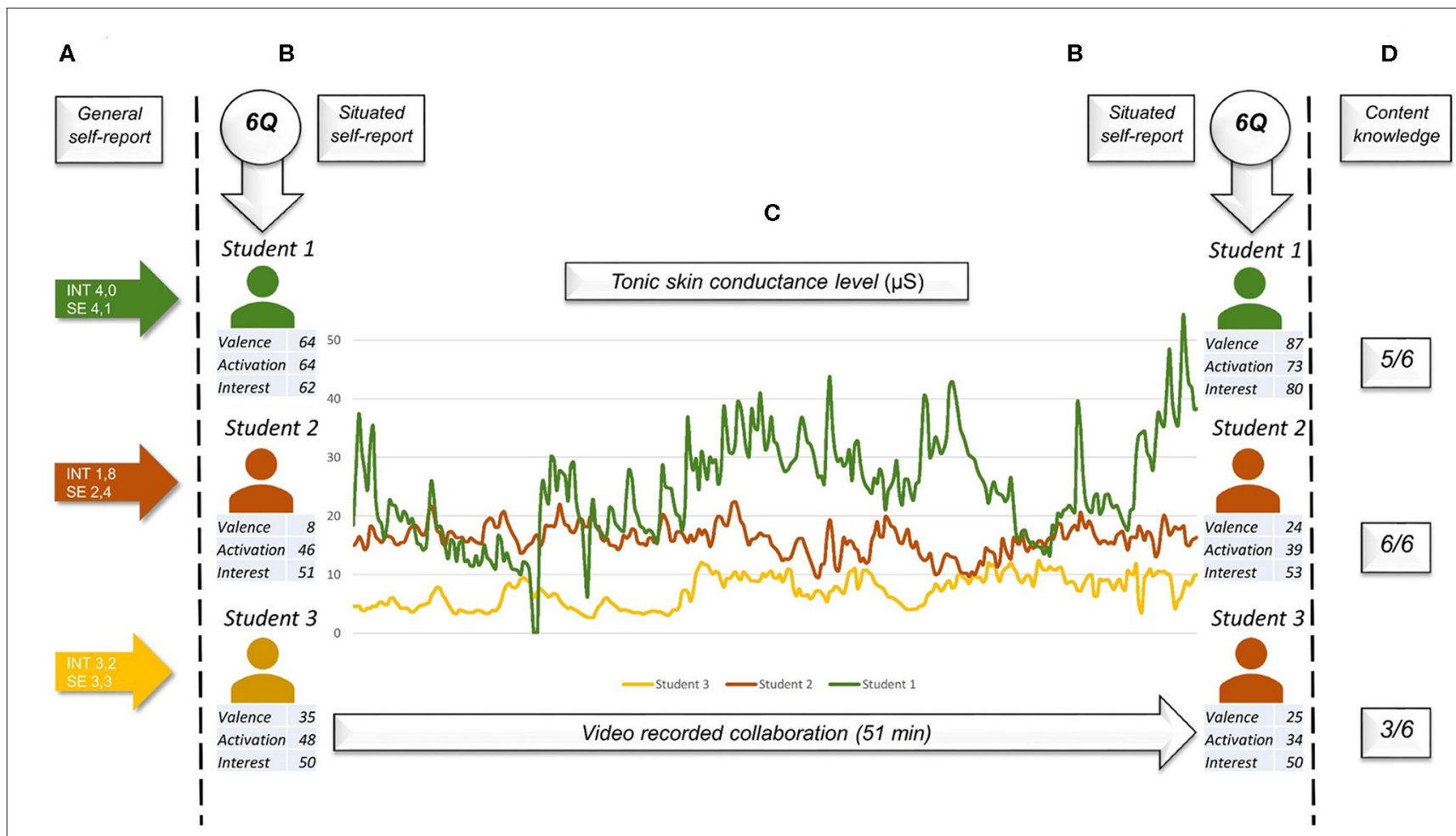

FIGURE 4 | A case example to illustrate how to combine data from different sources. The visualization includes students' (A) self-reported general science interest (INT) and self-efficacy (SE), (B) situated self-report data (6Q) of their emotional state (valence and activation) and task interest, (C) tonic skin conductance level during collaboration traced from EDA data, and (D) scores from the knowledge quiz completed after the lesson.

in valence from 8 to 24, whereas Student 3 has a slight decrease from 35 to 25, and both students remain in the medium levels of activation and interest. Thus, when aiming to understand and explain emotional and motivational effects on learning, more fine-grained process data are needed to capture contextual factors and situational variation during the learning process.

Next, the case example adds physiological data from each group member with their subjective general and situational appraisals. To obtain temporal online process data with high granularity, the students' emotional activation was measured with EDA. EDA data can be analyzed on both the individual and the group level, which provides possibilities for analyzing the socio-emotional aspects of collaborative learning. One dimension of the EDA measurement is the participants' slowly varying tonic skin conductance level (SCL) (Dawson et al., 2007; Boucsein, 2012). In the case example, EDA data during 51-min period of collaborative learning is presented for each student. The tonic SCL level of each student measured during collaboration is visible in colored lines in Figure 4. The example data was processed using MATLAB based software Ledalab (http://www. ledalab.de/). As the Shimmer3 GSR+ sensors produce data with the sampling rate of $128 \mathrm{~Hz}$, the data was first down sampled into $16 \mathrm{~Hz}$. The raw data was then decomposed into tonic and phasic components using continuous decomposition analysis (Benedek and Kaernbach, 2010b). The example shows that Student 1, who indicates a higher level of interest on the trait-type self-report and a high, increasing activation level related to her emotional state in $6 \mathrm{Q}$, shows both a high maximum level of SCL ( $54 \mu \mathrm{S})$ and high variation in SCL within the session. The two other students' SCL range, however, follows the degree of variation defined as normal in prior research (2-20 $\mathrm{SS}$; Dawson et al., 2007).

Another way to define students' arousal level is through the phasic short-term skin conductance response (SCR) peaks visualized in Figure 5 by the green, yellow, and red boxes under the SCL lines. SCR peaks are strongly associated with emotional responses caused by an external stimulus and are more reactive to variation than SCL (Dawson et al., 2007; Christopoulos et al., 2016). In situations with continuous stimuli, such as collaborative learning, the frequency of SCRs can be used as an indicator of the current arousal state (Dawson et al., 2007; Blascovich et al., 2011; Braithwaite et al., 2013). In the case example, the data was first smoothed out using an adaptive Gaussian filter and SCRs were then detected using the classical trough-to-peak technique (Benedek and Kaernbach, 2010a). Next, the number of peaks in each 1-min segment was calculated to define student's level of arousal in each minute: at rest, a frequency of 1-3 peaks/min occurs (Dawson et al., 2007), and frequencies higher than 20 peaks/min are considered as high arousal (Boucsein, 2012). While the students' SCL level could be used to follow individual group members' physiological arousal (in relation to other members), the SCR peaks could be beneficial in, for example, locating emotionally relevant, short-term high-arousal 


\section{Arousal state measured with the number of SCR peaks/min}

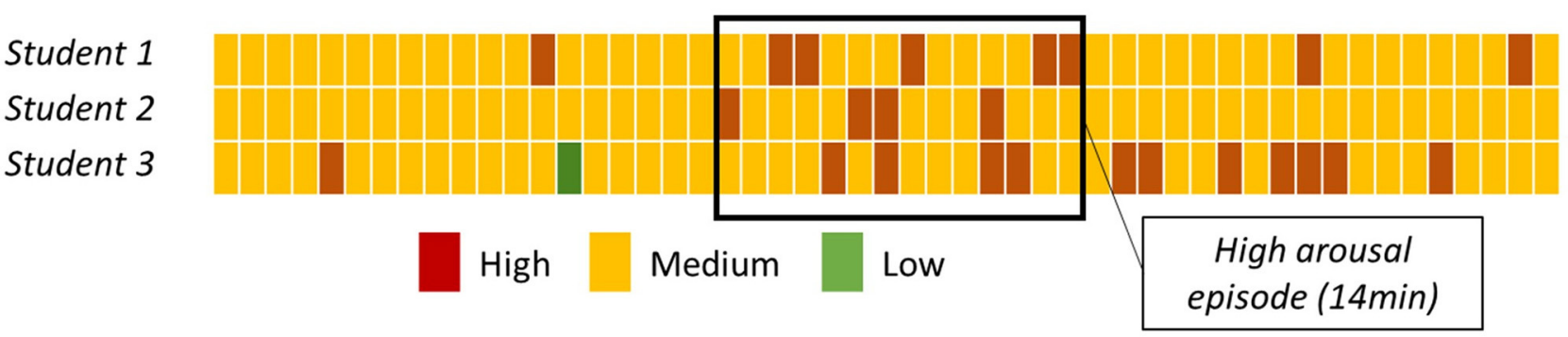

FIGURE 5 | The physiological arousal state (high, medium, low) of each student measured with the number of SCR peaks/min during the case example session. Each segment in the visualization corresponds to one minute of collaboration.

situations on a group level to be further investigated with qualitative data sources, such as video data, particularly when operating with a large amount of data. For example, in the case example, we would be interested in targeting the 14-min high-arousal episode to explore socioemotional interactions and possible challenges that could lead to the need for regulation and, further, actualized co- and socially shared motivation or emotion regulation.

To conclude, when studying motivation and emotion regulation via multimodal process data, each modality reveals a different motivational and emotional aspect influencing and shaping actualized motivation and emotion regulation, which is illustrated in Figure 4. The multimodal dataset can be used to explore the groups' learning process within one session as was mainly the case with the current example, but the real potential lies in the possibility to zoom in and out in terms of granularity, temporality, and cyclicity (Järvelä et al., 2019). Thus, multimodal (process) data afford opportunities to study emotion, motivation, and their regulation both within and across learning sessions, individuals, and collaborative groups. Individual learning patterns and paths can be cross-analyzed with their peers to unravel the role of different motivational and emotional factors in relation to social interaction, time, and other learning variables. Finally, multimodal data provide systematic ways to combine quantitative datasets with qualitative ones to profoundly analyze motivation, emotion, and their regulation as context- and situation-specific and as a part of the wider process of regulated learning.

\section{DISCUSSION}

Learning in technology-supported collaborative learning environments involves intricate, complex interactions among cognitive, metacognitive, motivational, affective, and social processes across specific tasks, topics, or domains, and learning contexts (Baker et al., 2013; Ludvigsen, 2016). Motivational and emotional hurdles seem to be particularly challenging to tackle in this complicated combination. Regardless of the profound advancement in theoretical understanding, many open questions concerning the multifaceted and situated function of "non-cognitive" aspects in collaborative groups' regulated learning remain unanswered (Järvenoja et al., 2018a). Emerging technologies offer opportunities to make these mental processes, such as the subjective experiences of affective reactions or motivational underpinnings or non-verbal emotional reactions, "visible" and, further, guide and support learners in becoming more conscious of the non-cognitive factors influencing their learning. As the possibilities of technology contribute to the understanding of the functioning of motivation and emotion in collaborative learning, more possibilities for technological tools to prompt and support the motivation and emotion regulation of collaborative learning also become available [e.g., Järvelä et al. (2015)].

In this paper, we have argued that an advanced understanding, particularly of motivation and emotion regulation and its various factors, is essential to harness the benefits of technology in supporting these processes in collaborative learning. Especially adolescent students who are yet developing abilities to function in the more demanding academic and social world (Gómez-Ortiz et al., 2016; Hollenstein and Lanteigne, 2018) can benefit from this type of support in learning situations. The dual aim of embedding the support of learning and regulation and data collection methods providing data on the fluctuating process of learning and interaction becomes concrete in the presented collaborative learning design. Our recommendation is to take both sides into account by providing support for learners while simultaneously collecting data on motivational and emotional aspects contributing to socially shared regulation processes. Accordingly, we highlight that both aspects should be addressed explicitly in the learning and research designs. From the research perspective, this provides possibilities for data collection that corresponds to educational change and, particularly, to a need for ecologically valid analyses and results related to regulation in collaborative learning (Belland et al., 2013; Wise and Schwarz, 2017; Järvenoja et al., 2018a). From the learner-support perspective it is essential to share the understanding of the role of regulation for collaborative learning with schools and teachers. The teachers are in a key role in implementing the collaborative learning designs and 
support in practice (Van Leeuwen and Janssen, 2019). To do that, they need information that is built on prior research evidence and justified theoretical assumptions focusing on the implementation of the collaborative learning designs. To build up premises for collaboration between researchers and teachers, we stress the importance of introducing descriptions of research designs and justifications behind the certain (practical) choices, as we have done in this article. Interdisciplinary regulated learning research is currently progressing (Azevedo and Gašević, 2019), and along with this progress, opportunities for understanding and promoting adaptive motivation and emotion develops. The use of multimodal learning process data could become new "channels" for identifying processes that have been impossible to achieve with conventional educational psychology research methods (Azevedo, 2015). For example, Dindar et al. (2019) studied regulation processes in the collaborative learning of physics through situated self-reports, physiological signals, and academic achievement. Their study showed that situated measures of motivation regulation predict academic achievement. Also, the between student concordance in self-reports of motivation, cognition, and behavior was found to be related to concordance in physiological signals. The results demonstrate the complexity of the relationships between SRL variables and show the potential value of physiological measures when studying learning processes. Similarly, a study conducted by Taub et al. (2019) demonstrates how multimodality can reveal the connections between emotions and the metacognitive aspects of regulation processes when students learn with the assistance of a hypermedia-based intelligent tutoring system. In their study, students' emotions were traced through automatic facial expression analysis and investigated in relation to the accuracy of students' self-reported monitoring judgments. The results of these and related studies increase the understanding of the value of emotions in the learning process. Also, Harley et al. (2019) gathered multimodal data covering the experiential and physiological components of medical students' emotions during a diagnostic reasoning task. In their study, they examined the relationships between students' self-reported habitual emotion regulation strategies, physiological activation measured through electrodermal activity (EDA), self-reported emotions and appraisals, and academic achievement. They found that the students' skin conductance level (SCL) positively predicted anxiety and shame, whereas skin conductance response (SCR) was associated with higher academic achievement. Furthermore, emotion regulation tendencies predicted physiological arousal during the learning situation.

Today, physiological devices are mostly used to track, for example, health-related information, but all of the abovementioned studies are examples of how researchers have used multimodal data to relate motivational and emotional process data to other learning components. While prominent empirical research exploring the possibilities of different types of data channels is emerging, [e.g., Haataja et al. (2018), Malmberg et al. (2019)], we are still in the process of discovering the relevant combinations of different data sources and proper ways to combine data from different channels to track learning. To trace motivation and emotion regulation from process data and to explain the conditions and products to which it is bound (Bakhtiar et al., 2018), we need data from different aspects of collaborative learning process and from individuals participating in collaboration in their natural learning environments. While multimodal and process-oriented approaches have started to emerge also in the field of learning sciences, researchers are faced with various challenges that come along. These challenges span from designing and conducting complex research design to the issues in analyzing complex, nested and time-bound data, which varies in granularity and source. In the field of learning science and among researchers engaged in process-oriented learning research, there is an on-going discussion on the need to share not only the successful results from empirical studies, but also to share in more detail the research designs and ideas for analyses (Harteis et al., 2018; Winne, 2019). To progress as a field, it is essential to share the premises of these researches, practical experiences, and overall designs that are all built on prior research evidence and justified theoretical assumptions. In addition, more extensive and interdisciplinary efforts are needed in basic research on emotion and motivation to reach the full potential of the available emerging technology and digitalization for human learning. If we manage to share our understanding more comprehensively, we can reach the potential of the unobtrusive multimodal data channels and transfer their power to tools that provide learners "on the fly" support when needed.

\section{DATA AVAILABILITY STATEMENT}

The datasets generated for this study will not be made publicly available. The dataset includes personalized data from minor participants. The research permission approved by the ethics committee delimits the use of data to the research group members.

\section{ETHICS STATEMENT}

The studies involving human participants were reviewed and approved by Ethics Committee of Human Sciences, University of Oulu (https://www.oulu.fi/eudaimonia/node/19813). Written informed consent to participate in this study was provided by the participants' legal guardian/next of kin. Written informed consent was obtained from the minor(s)' legal guardian/next of kin for the publication of any potentially identifiable images or data included in this article.

\section{AUTHOR CONTRIBUTIONS}

HJ, JM, and SJ were responsible for the theoretical, researchbased aims of the research project, scientific design principles of the collaborative learning design, and data collection. They also hold the main funding of the research. KM, TT, EH, and SA were responsible for running the design and collecting the data. HJ was primarily responsible for structuring the manuscript, while TT was primarily responsible for the case example. All authors 
contributed to writing and editing, participated in designing the learning design, and planning the data collection process.

\section{FUNDING}

This work was supported by the Academy of Finland [Grant numbers 297686 (HJ) and 308809 (JM)], University of Oulu (SJ), and the Finnish Cultural Foundation (TT).

\section{REFERENCES}

Ainley, M., Hidi, S., and Berndorff, D. (2002). Interest, learning, and the psychological processes that mediate their relationship. J. Educ. Psychol. 94, 545-561. doi: 10.1037/0022-0663.94.3.545

Ainley, M., and Patrick, L. (2006). Measuring self-regulated learning processes through tracking patterns of student interaction with achievement activities. Educ. Psychol. Rev. 18, 267-286. doi: 10.1007/s10648-006-9018-z

Azevedo, R. (2005). Using hypermedia as a metacognitive tool for enhancing student learning? the role of self-regulated learning. Educ. Psychol. 40, 199-209. doi: $10.1207 /$ s15326985ep4004_2

Azevedo, R. (2015). Defining and measuring engagement and learning in science: conceptual, theoretical, methodological, and analytical issues. Educ. Psychol. 50, 84-94. doi: 10.1080/00461520.2015.1004069

Azevedo, R., and Gašević, D. (2019). Analyzing multimodal multichannel data about self-regulated learning with advanced learning technologies: issues and challenges. Comp. Hum. Behav. 96, 207-210. doi: 10.1016/j.chb.2019.03.025

Azevedo, R., and Witherspoon, A. M. (2009). "Self-regulated learning with hypermedia," in Handbook of Metacognition in Education, eds D. J. Hacker, J. Dunlosky and A. C. Graesser (New York, NY: Routledge), 319-339.

Baker, M. J. (2015). Collaboration in collaborative learning. Interact. Stud. 16, 451-473. doi: 10.1075/is.16.3.05bak

Baker, M. J., Andriessen, J., and Järvelä, S. (2013). "Introduction: visions of learning together," in Affective Learning Together: Social and Emotional Dimensions of Collaborative Learning, eds M. J. Baker, J. Andriessen, and S. Järvelä (Abingdon, UK: Routledge), 1-30. doi: 10.4324/9780203069684

Bakhtiar, A., Webster, E. A., and Hadwin, A. F. (2018). Regulation and socioemotional interactions in a positive and a negative group climate. Metacogn. Learn. 13, 57-90. doi: 10.1007/s11409-017-9178-x

Belland, B. R., Kim, C., and Hannafin, M. J. (2013). A framework for designing scaffolds that improve motivation and cognition. Educ. Psychol. 48, 243-270. doi: 10.1080/00461520.2013.838920

Benedek, M., and Kaernbach, C. (2010a). A continuous measure of phasic electrodermal activity. J. Neurosci. Methods 190, 80-91. doi: 10.1016/j.jneumeth.2010.04.028

Benedek, M., and Kaernbach, C. (2010b). Decomposition of skin conductance data by means of nonnegative deconvolution. Psychophysiology 47, 647-658. doi: 10.1111/j.1469-8986.2009.00972.x

Ben-Eliyahu, A., and Linnenbrink-Garcia, L. (2013). Extending self-regulated learning to include self-regulated emotion strategies. Motiv. Emot. 37, 558-573. doi: $10.1007 / \mathrm{s} 11031-012-9332-3$

Blascovich, J., Mendes, W. B., Vanman, E., and Dickerson, S. (2011). Social Psychophysiology for Social and Personality. London: Sage. doi: $10.4135 / 9781446287842$

Boekaerts, M. (2011). "Emotions, emotion regulation, and self-regulation of learning," in Handbook of Regulation of Learning and Performance, eds B. J. Zimmerman and D. H. Schunk (New York, NY: Routledge), 408-425.

Boekaerts, M., and Pekrun, R. (2015). "Emotions and emotion regulation in academic settings," in Handbook of Educational Psychology, 3rd Edn, eds L. Corno, and E. M. Anderman (New York, NY: Routledge), 76-90.

Boucsein, W. (2012). Electrodermal Activity. Boston, MA: Springer Science and Business Media.

Braithwaite, J. J., Watson, D. G., Jones, R., and Rowe, M. (2013). A guide for analysing electrodermal activity (EDA) \& skin conductance responses (SCRs) for psychological experiments. Psychophysiology 49, 1017-1034. doi: $10.1111 / j .1469-8986.2012 .01384 . x$

\section{ACKNOWLEDGMENTS}

This research was conducted at the Ritaharju School, City of Oulu, Finland in collaboration with school's science teachers and school management. Data collection was carried out with the support of LeaF Research Infrastructure (https://www.oulu.fi/leaf-eng/), University of Oulu, Finland.

Chanel, G., Lalanne, D., Lavoué, E., Lund, K., Molinari, G., Ringeval, F., et al. (2016). "Grand challenge problem 2: adaptive awareness for social regulation of emotions in online collaborative learning environments," in Grand Challenge Problems in Technology-Enhanced Learning II: MOOCs and Beyond, eds J. Eberle, K. Lund, P. Tchounikine, and F. Fischer (Cham: Springer), 13-16.

Christopoulos, G. I., Uy, M. A., and Yap, W. J. (2016). The body and the brain: measuring skin conductance responses to understand the emotional experience. Organ. Res. Methods 22, 394-420. doi: 10.1177/1094428116681073

Cleary, T. J. (2006). The development and validation of the selfregulation strategy inventory-self-report. J. School Psychol. 44, 307-322. doi: $10.1016 /$ j.jsp.2006.05.002

Cohen, E. G. (1994). Restructuring the classroom: conditions for productive small groups. Rev. Educ. Res. 64, 1-35. doi: 10.3102/00346543064001001

Corno, L., and Kanfer, R. (1993). Chapter 7: the role of volition in learning and performance. Rev. Res. Educ. 19, 301-341. doi: 10.3102/0091732X019001301

Dawson, M. E., Schell, A. M., and Filion, D. M. (2007). "The electrodermal system," in Handbook of Psychophysiology, 3rd Edn, eds J. Cacioppo, L. G. Tassinary, and G. G. Berntson (Cambridge: Cambridge University Press), 159-181.

Diamond, L. M., and Aspinwall, L. G. (2003). Emotion regulation across the life span: an integrative perspective emphasizing self-regulation, positive affect, and dyadic processes. Motiv. Emot. 27, 125-156. doi: 10.1023/A:1024521920068

DiDonato, N. C. (2013). Effective self-and co-regulation in collaborative learning groups: an analysis of how students regulate problem solving of authentic interdisciplinary tasks. Instr. Sci. 41, 25-47. doi: 10.1007/s11251-0129206-9

Dindar, M., Malmberg, J., Järvelä, S., Haataja, E., and Kirschner, P. A. (2019). Matching self-reports with electrodermal activity data: investigating temporal changes in self-regulated learning. Educ. Info. Tech. 25, 1785-1802. doi: 10.1007/s10639-019-10059-5

Efklides, A., Papadaki, M., Papantoniou, G., and Kiosseoglou, G. (1998). Individual differences in feelings of difficulty: the case of school mathematics. Eur. J. Psychol. Educ. 13, 207-226. doi: 10.1007/BF03173090

Efklides, A., Schwartz, B. L., and Brown, V. (2018). "Motivation and affect in selfregulated learning: Does metacognition play a role?" in Educational Psychology Handbook Series. Handbook of Self-regulation of Learning and Performance, eds D. H. Schunk and J. A. Greene (Routledge/Taylor \& Francis Group), 64-82. doi: 10.4324/9781315697048-5

Fischer, F., Kollar, I., Stegmann, K., and Wecker, C. (2013). Toward a script theory of guidance in computer-supported collaborative learning. Educ. Psychol. 48, 56-66. doi: 10.1080/00461520.2012.748005

Goetz, T., Becker, E. S., Bieg, M., Keller, M. M., Frenzel, A. C., and Hall, N. C. (2015). The glass half empty: how emotional exhaustion affects the statetrait discrepancy in self-reports of teaching emotions. PLoS ONE 10, 1-14. doi: 10.1371/journal.pone.0137441

Goetz, T., Sticca, F., Pekrun, R., Murayama, K., and Elliot, A. J. (2016). Intraindividual relations between achievement goals and discrete achievement emotions: an experience sampling approach. Learn. Instr. 41, 115-125. doi: 10.1016/j.learninstruc.2015.10.007

Gómez-Ortiz, O., Romera, E. M., Ortega-Ruiz, R., Cabello-González, R., and y Fernández-Berrocal, P. (2016). Analysis of emotion regulation in Spanish adolescents: validation of the emotion regulation questionnaire. Front. Psychol. 6:1959. doi: 10.3389/fpsyg.2015.01959

Griffin, P., Care, E., and McGaw, B. (2012). "The changing role of education and schools," in Assessment and Teaching of 21st Century Skills, eds P. Griffin, B. McGaw, and E. Care (New York, NY: Springer), 1-15. doi: 10.1007/978-94-007-2324-5_1 
Gross, J. J. (1998). Antecedent-and response-focused emotion regulation: divergent consequences for experience, expression, and physiology. J. Pers. Soc. Psychol. 74, 224-237. doi: 10.1037/0022-3514.74.1.224

Haataja, E., Malmberg, J., and Järvelä, S. (2018). Monitoring in collaborative learning: co-occurrence of observed behavior and physiological synchrony explored. Comp. Hum. Behav. 87, 337-347. doi: 10.1016/j.chb.2018.06.007

Hadwin, A., Järvelä, S., and Miller, M. (2017). "Self-regulation, co-regulation and shared regulation in collaborative learning environments," in Handbook of SelfRegulation of Learning and Performance, eds D. H. Schunk and J. F. Greene (London: Routledge), 83-106 doi: 10.4324/9781315697048-6

Hadwin, A. F., Bakhtiar, A., and Miller, M. (2018). Challenges in online collaboration: effects of scripting shared task perceptions. Int. J. Comp. Support. Learn. 13, 301-329. doi: 10.1007/s11412-018-9279-9

Harley, J. M., Jarrell, A., and Lajoie, S. P. (2019). Emotion regulation tendencies, achievement emotions, and physiological arousal in a medical diagnostic reasoning simulation. Instr. Sci. 47, 151-180. doi: 10.1007/s11251-018-09480-z

Harteis, C., Kok, E., and Jarodzka, H. (2018). The journey to proficiency: exploring new objective methodologies to capture the process of learning and professional development. Front. Learn. Res. 6, 1-5. doi: 10.14786/flr.v6i3.435

Hmelo-Silver, C. E. (2004). Problem-based learning: what and how do students learn? Educ. Psychol. Rev. 16, 235-266. doi: 10.1023/B:EDPR.0000034022.16470.f3

Hmelo-Silver, C. E., Chinn, C. A., Chan, C., and O'Donnell, A. M. (2013). "Information processing approaches to collaborative learning," in The international Handbook of Collaborative Learning, eds C. E. Hmelo-Silver, C. A. Chinn, C. Chan, and A. M. O'Donnell (New York, NY: Routledge), 31-52. doi: $10.4324 / 9780203837290$

Hollenstein, T., and Lanteigne, D. M. (2018). "Emotion regulation dynamics in adolescence," in Emotion Regulation: A Matter of Time, eds P. M. Cole and T. Hollenstein (New York, NY: Routledge), 158-176.

Iiskala, T., Vauras, M., Lehtinen, E., and Salonen, P. (2011). Socially shared metacognition of dyads of pupils in collaborative mathematical problem-solving processes. Learn. Instr. 21, 379-393. doi: 10.1016/j.learninstruc.2010.05.002

Janssen, J., and Bodemer, D. (2013). Coordinated computer-supported collaborative learning: awareness and awareness tools. Educ. Psychol. 48, 40-55. doi: 10.1080/00461520.2012.749153

Järvelä, S., Hadwin, A. F., Malmberg, J., and Miller,. M. (2017). "Contemporary perspectives of regulated learning in collaboration," in Handbook of the Learning Sciences, eds F. Fischer, C. E. Hmelo-Silver, P. Reimann, and S. R. Goldman (New York, NY: Routledge), 127-136. doi: 10.4324/9781315617572-13

Järvelä, S., Järvenoja, H., Malmberg, J., and Hadwin, A. F. (2013). Exploring socially shared regulation in the context of collaboration. J. Cogn. Educ. Psychol. 12, 267-286. doi: 10.1891/1945-8959.12.3.267

Järvelä, S., Järvenoja, H., and Muukkonen, H. (2020). "Motivation in collaborative inquiry environments," in The International Handbook of Inquiry and Learning, eds C. Chinn, R. Duncan, S. Goldman, and M. Kapur (Routledge).

Järvelä, S., Kirschner, P. A., Hadwin, A., Järvenoja, H., Malmberg, J., Miller, M., et al. (2016). Socially shared regulation of learning in CSCL: understanding and prompting individual- and group-level shared regulatory activities. Int. J. Comp. Support. Collaborat. Learn. 11, 263-280. doi: 10.1007/s11412-016-9238-2

Järvelä, S., Kirschner, P. A., Panadero, E., Malmberg, J., Phielix, C., Jaspers, J., et al. (2015). Enhancing socially shared regulation in collaborative learning groups: designing for CSCL regulation tools. Educ. Tech. Res. Dev. 63, 125-142. doi: $10.1007 / \mathrm{s} 11423-014-9358-1$

Järvelä, S., Malmberg, J., Haataja, E., Sobocinski, M., and Kirschner, P. A. (2019). What multimodal data can tell us about the students' regulation of their learning process? Learn. Instr. doi: 10.1016/j.learninstruc.2019.04.004. [Epub ahead of print].

Järvelä, S., and Renniger, K. R. (2014). "Designing for learning: engagement, interest, and motivation," in The Cambridge Handbook of the Learning Sciences, 2nd Edn, ed K. R. Sawyer (New York, NY: Cambridge University Press), 668-685. doi: 10.1017/CBO9781139519526.040

Järvenoja, H., Järvelä, S., and Malmberg, J. (2017). Supporting groups' emotion and motivation regulation during collaborative learning. Learn. Instr. doi: 10.1016/j.learninstruc.2017.11.004. [Epub ahead of print].
Järvenoja, H., Järvelä, S., and Malmberg, J. (2015). Understanding regulated learning in situative and contextual frameworks. Educ. Psychol. 50, 204-219. doi: $10.1080 / 00461520.2015 .1075400$

Järvenoja, H., Järvelä, S., Törmänen, T., Näykki, P., Malmberg, J., Kurki, K., et al. (2018a). Capturing motivation and emotion regulation during a learning process. Front. Learn. Res. 6:369. doi: 10.14786/flr.v6i3.369

Järvenoja, H., Malmberg, J., Järvelä, S., Näykki, P., and Kontturi, H. (2018b). Investigating students' situation-specific emotional state and motivational goals during a learning project within one primary school classroom. Learn. Res. Pract. 5, 1-20. doi: 10.1080/23735082.2018.1554821

Järvenoja, H., Volet, S., and Järvelä, S. (2013). Regulation of emotions in socially challenging learning situations: an instrument to measure the adaptive and social nature of the regulation process. Educ. Psychol. 33, 31-58. doi: 10.1080/01443410.2012.742334

Jovanovic, J., Mirriahi, N., Gašević, D., Dawson, S., and Pardo, A. (2019). Predictive power of regularity of pre-class activities in a flipped classroom. Comp. Educ. 134, 156-168. doi: 10.1016/j.compedu.2019.02.011

Ketonen, E. E., Dietrich, J., Moeller, J., Salmela-Aro, K., and Lonka, K. (2018). The role of daily autonomous and controlled educational goals in students' academic emotion states: an experience sampling method approach. Learn. Instr. 53, 10-20. doi: 10.1016/j.learninstruc.2017.07.003

Kirschner, P. A., Sweller, J., Kirschner, F., and Zambrano, J. (2018). From cognitive load theory to collaborative cognitive load theory. Int. J. Comp. Support. Collaborat. Learn. 13, 213-233. doi: 10.1007/s11412-018-9277-y

Koivuniemi, M., Panadero, E., Malmberg, J., and Järvelä, S. (2017). Higher education students' learning challenges and regulatory skills in different learning situations/Desafíos de aprendizaje y habilidades de regulación en distintas situaciones de aprendizaje en estudiantes de educación superior. Infancia y Aprendizaje 40, 19-55. doi: 10.1080/02103702.2016.1272874

Kreibig, S. D., and Gendolla, G. H. E. (2014). "Autonomic nervous system measurement of emotion in education and achievement settings," in International Handbook of Emotions in Education, eds R. Pekrun and L. Linnenbrink-Garcia (New York, NY: Routledge), 625-642.

Kuhn, D. (2015). Thinking together and alone. Educ. Res. 44, 46-53. doi: 10.3102/0013189X15569530

Lajoie, S. P., Lee, L., Poitras, E., Bassiri, M., Kazemitabar, M., Cruz-Panesso, I., et al. (2015). The role of regulation in medical student learning in small groups: regulating oneself and others' learning and emotions. Comp. Hum. Behav. 52, 601-616. doi: 10.1016/j.chb.2014.11.073

Linnenbrink-Garcia, L., Patall, E. A., and Pekrun, R. (2016). Adaptive motivation and emotion in education: research and principles for instructional design. Policy Insights Behav. Brain Sci. 3, 228-236. doi: 10.1177/2372732216644450

Ludvigsen, S. (2016). CSCL: connecting the social, emotional and cognitive dimensions. Int. J. Comp. Support. Collaborat. Learn. 11, 115-121. doi: 10.1007/s11412-016-9236-4

Mäkitalo-Siegl, K., and Fischer, F. (2013). "Help seeking in computer-supported collaborative science learning environments," in Advances in Help-seeking Research and Applications: The Role of Emerging Technologies, eds S. A. Karabenick and M. Puustinen (Charlotte, NC: IAP), 99-120.

Malmberg, J., Järvelä, S., Holappa, J., Haataja, E., Huang, X., and Siipo, A. (2019). Going beyond what is visible: what multichannel data can reveal about interaction in the context of collaborative learning? Comp. Hum. Behav. 96, 235-245. doi: 10.1016/j.chb.2018.06.030

Malmberg, J., Järvelä, S., Järvenoja, H., and Panadero, E. (2015). Promoting socially shared regulation of learning in CSCL: progress of socially shared regulation among high-and low-performing groups. Comp. Hum. Behav. 52, 562-572. doi: 10.1016/j.chb.2015.03.082

Mayer, R. E., and Moreno, R. (1998). A cognitive theory of multimedia learning: implications for design principles. J. Educ. Psychol. 91, 358-368. doi: $10.1037 / 0022-0663.91 .2 .358$

Mikroyannidis, A., Okada, A., Scott, P., Rusman, E., Specht, M., Stefanov, K., et al. (2013). WeSPOT: a personal and social approach to inquiry-based learning. J. Univ. Comp. Sci. 19, 2093-2111. doi: 10.3217/jucs-019-14

Miller, M., and Hadwin, A. (2015). Scripting and awareness tools for regulating collaborative learning: changing the landscape of support in CSCL. Comp. Hum. Behav. 52, 573-588. doi: 10.1016/j.chb.2015.01.050

Miyake, N. (1986). Constructive interaction and the iterative process of understanding. Cogn. Sci. 10, 151-177. doi: 10.1207/s15516709cog1002_2 
Moeller, J., Ivcevic, Z., Brackett, M. A., and White, A. E. (2018). Mixed emotions: network analyses of intra-individual co-occurrences within and across situations. Emotion 18, 1106-1121. doi: 10.1037/emo0000419

Mullins, D., Rummel, N., and Spada, H. (2011). Are two heads always better than one? differential effects of collaboration on students' computer-supported learning in mathematics. Int. J. Comp. Support. Collaborat. Learn. 6, 421-443. doi: 10.1007/s11412-011-9122-z

Op't Eynde, P., and Turner, J. E. (2006). Focusing on the complexity of emotion issues in academic learning: a dynamical component systems approach. Educ. Psychol. Rev. 18, 361-376. doi: 10.1007/s10648-006-9031-2

Pecchinenda, A., and Smith, C. A. (1996). The affective significance of skin conductance activity during a difficult problem-solving task. Cogn. Emot. 10, 481-504. doi: 10.1080/026999396380123

Pekrun, R. (2016). "Academic emotions," in Handbook of Motivation at School, 2nd $E d n$, eds K. R. Wentzel and D. B. Miele (New York, NY: Routledge), 120-144.

Pekrun, R., Frenzel, A. C., Goetz, T., and Perry, R. P. (2007). "The control-value theory of achievement emotions: an integrative approach to emotions in education," in Emotion in Education, eds P. A. Schutz, and R. Pekrun (San Diego, CA: Elsevier Inc. Academic Press), 13-36. doi: 10.1016/B978-012372545-5/50003-4

Perry, N. E. (1998). Young children's self-regulated learning and contexts that support it. J. Educ. Psychol. 90, 715-729. doi: 10.1037/0022-0663.90.4.715

Pijeira-Díaz, H. J., Drachsler, H., Kirschner, P. A., and Järvelä, S. (2018). Profiling sympathetic arousal in a physics course: how active are students? J. Comp. Assist. Learn. 34, 397-408. doi: 10.1111/jcal.12271

Roschelle, J., and Teasley, S. D. (1995). The construction of shared knowledge in collaborative problem solving. Comp. Support. Collab. Learn. 128, 69-97. doi: 10.1007/978-3-642-85098-1_5

Sawyer, K. (2014). "Introduction: the new science of learning," in The Cambridge Handbook of the Learning Sciences, 2nd Edn, ed K. R. Sawyer (New York, NY: Cambridge University Press), 1-18. doi: 10.1017/CBO9781139519526.002

Schnaubert, L., and Bodemer, D. (2019). Providing different types of group awareness information to guide collaborative learning. Int. J. Comp. Support. Collab. Learn. 14, 1-45. doi: 10.1007/s11412-018-9293-y

Schraw, G., and Dennison, R. S. (1994). Assessing metacognitive awareness. Contemp. Educ. Psychol. 19, 460-475. doi: 10.1006/ceps.1994.1033

Schutz, P. A., and Pekrun, R. (2007). "Introduction to emotion in education," in Emotion in Education, eds P. A. Schutz, and R. Pekrun (San Diego, CA: Academic Press), 3-10. doi: 10.1016/B978-012372545-5/50002-2

Shapiro, A., and Niederhauser, D. (2004). "Learning from hypertext: research issues and findings," in Handbook of Research on Educational Communications and Technology, ed D. H. Jonassen (Lawrence Erlbaum Associates Publishers), 605-520.

Tapola, A., Veermans, M., and Niemivirta, M. (2013). Predictors and outcomes of situational interest during a science learning task. Instr. Sci. 41, 1047-1064. doi: 10.1007/s11251-013-9273-6

Taub, M., Azevedo, R., Rajendran, R., Cloude, E. B., Biswas, G., and Price, M. J. (2019). How are students' emotions related to the accuracy of cognitive and metacognitive processes during learning with an intelligent tutoring system? Learn. Instr. doi: 10.1016/j.learninstruc.2019.04.001. [Epub ahead of print].

Thompson, L., and Fine, G. A. (1999). Socially shared cognition, affect, and behavior: a review and integration. Pers. Soc. Psychol. Rev. 3, 278-302. doi: $10.1207 /$ s15327957pspr0304_1

Törmänen, T., Järvenoja, H., and Mänty, K. (2020). Exploring Groups' Affective States During Collaborative Learning - What Triggers Activating Affect on a Group Level?

Usher, E. L., and Pajares, F. (2008). Sources of self-efficacy in school: critical review of the literature and future directions. Rev. Educ. Res. 78, 751-796. doi: $10.3102 / 0034654308321456$
Van Leeuwen, A., and Janssen, J. (2019). A systematic review of teacher guidance during collaborative learning in primary and secondary education. Educ. Res. Rev. 27, 71-89. doi: 10.1016/j.edurev.2019.02.001

Volet, S., Vauras, M., and Salonen, P. (2009). Self-and social regulation in learning contexts: an integrative perspective. Educ. Psychol. 44, 215-226. doi: $10.1080 / 00461520903213584$

Volet, S. E. (2001). "Significance of cultural and motivational variables on students' appraisals of group work," in Student Motivation: the Culture and Context of Learning, eds F. Salili, C. Y. Chiu, and Y. Y. Hong (New York, NY: Plenum), 309-334.

Volet, S. E., and Järvelä, S. E. (2001). Motivation in Learning Contexts: Theoretical Advances and Methodological Implications. (New York, NY: Pergamon Press).

Von Glasersfeld, E. (1998). "Cognition, construction of knowledge, and teaching," in Constructivism in Science Education, ed M. R. Matthews (Dordrecht: Springer), 11-30. doi: 10.1007/978-94-011-5032-3_2

Wang, X., Kollar, I., and Stegmann, K. (2017). Adaptable scripting to foster regulation processes and skills in computer-supported collaborative learning. Int. J. Comp. Support. Collab. Learn. 12, 153-172. doi: 10.1007/s11412-017-9254-x

Webb, N. M., Troper, J. D., and Fall, R. (1995). Constructive activity and learning in collaborative small groups. J. Educ. Psychol. 87, 406-423. doi: $10.1037 / 0022-0663.87 .3 .406$

Weiner, B. (1985). An attributional theory of achievement motivation and emotion. Psychol. Rev. 92, 548-573. doi: 10.1037/0033-295X.92.4.548

Winne, P. H. (2018). Theorizing and researching levels of processing in selfregulated learning. Br. J. Educ. Psychol. 88, 9-20. doi: 10.1111/bjep.12173

Winne, P. H. (2019). Paradigmatic dimensions of instrumentation and analytic methods in research on self-regulated learning. Comp. Hum. Behav. 96, 285-289. doi: 10.1016/j.chb.2019.03.026

Winne, P. H., and Hadwin, A. F. (2013). "nStudy: tracing and supporting selfregulated learning in the internet," in International Handbook of Metacognition and Learning Technologies, eds R. Azevedo and V. Aleven (New York, NY: Springer), 293-308.

Wise, A. F., and Schwarz, B. B. (2017). Visions of CSCL: eight provocations for the future of the field. Int. J. Comp. Support. Collab. Learn. 12, 423-467. doi: 10.1007/s11412-017-9267-5

Wolters, C. A., and Benzon, M. B. (2013). Assessing and predicting college students' use of strategies for the self-regulation of motivation. J. Exp. Educ. 81, 199-221. doi: 10.1080/00220973.2012.699901

Zimmerman, B. J. (2000). "Attaining self-regulation," in Handbook of SelfRegulation, eds M. Boekaerts, P. R. Pintrich, and M. Zeidner (San Diego, CA: Elsevier), 13-39.

Conflict of Interest: The learning design structure, the $6 \mathrm{Q}$ tool, and the knowledge quiz were implemented in Qridi ${ }^{\circledR}$ software in collaboration with the software developer (http://www.qridi.com). None of the authors received any financial gain from the collaboration.

The authors declare that the research was conducted in the absence of any commercial or financial relationships that could be construed as a potential conflict of interest.

Copyright (c) 2020 Järvenoja, Malmberg, Törmänen, Mänty, Haataja, Ahola and Järvelä. This is an open-access article distributed under the terms of the Creative Commons Attribution License (CC BY). The use, distribution or reproduction in other forums is permitted, provided the original author(s) and the copyright owner(s) are credited and that the original publication in this journal is cited, in accordance with accepted academic practice. No use, distribution or reproduction is permitted which does not comply with these terms. 